\title{
Building Resilience in the Time of Super Typhoons: Evaluating the First Filipino Design-Build University Program
}

\author{
ANNA KOOSMANN \\ University of Arizona
}

This paper highlights the value of post-occupancy evaluations (POEs) in the context of adapting U.S. design-build pedagogy to a Filipino university. Since the 1990's, hands-on design-build programs have become popularized for creating positive impact on students in the U.S. Today, they are being adapted globally, but there is insufficient research on design-build programs and their impact on communities, and even more so, on the emerging programs in foreign universities. Rather, published design-build projects typically focus on the design process, innovation, execution, and putting emphasis on design awards. It is less common to find postoccupancy and beneficiary impact. This might be due to the lack of standardized methods and resources for carrying out POEs. Following-up and reporting the impact of design-build projects through POEs is worth expanding upon, and they are an essential instrument for building resilient communities, especially since many architecture programs today offer some form of hands-on, service-learning as an alternative to traditional architecture education. ${ }^{1}$

In 2013, Super Typhoon Haiyan was one of the strongest storms to strike the earth, reaching wind speeds up to $195 \mathrm{mph}$, causing massive destruction in the Philippines. ${ }^{2}$ Situated in the Pacific Ocean "ring of fire," the Philippines is vulnerable to extreme weather and earthquakes. This is challenging Filipinos to reform architecture education for resilience. "Building Resilience in the Time of Super Typhoons" evaluates the first, university design-build program in the Philippines. Estudio Damgo (Dream Studio) is patterned after those in the United States. Founded in 2012, Filipino architecture students are given the chance to put theory into practice; by researching, designing, and constructing a small structure for a chosen community. Students gain hands-on experience using native materials in a context of community input and support. Furthermore, the program provides the beneficiary with a unique, sustainable and affordable asset that showcases innovation in the changing face of architecture. 26 graduates and 5 community projects have been completed in 2017 . The research (spanning 2012 - 2015) evaluates the impact of the program on the university students and their target communities. Projects include a preschool classroom in a rural mountain village, a multipurpose building in a farming village for 100 displaced flood survivors, and a floating structure at the marine sanctuary. Qualitative studies were conducted over a 5-month period in 2015 that utilized questionnaires, post-occupancy evaluations, on-site observations, and interviews. The results were documented and summarized into best practices, lessons learned, and comparative case studies that were presented to the university to improve and institutionalize the program for long-term success. The study also helped improve stakeholder partnerships with the community beneficiaries. This research provides insights into the complexities of adapting a design-build pedagogy to reform Filipino architectural education. This is a paradigm shift, and it has raised the bar in architecture education in the Philippines with acclaimed initiatives and international recognition since its launch in 2012. Storms like Super Typhoon Haiyan are becoming stronger and more frequent, putting the Philippines seasonally at risk. It is time to adopt a grassroots approach to build resilient communities in developing nations from the inside. Educating emerging professionals within their local context serves as an alternative to the global initiatives that are tackling catastrophic crisis from the outside. This program fosters the spread of a local, architectural language inherent to Filipinos' place and cultural values, and it can serve as a model in developing nations worldwide.

\section{INTRODUCTION}

The Filipino design-build program, Estudio Damgo (Dream Studio), was established in 2012 at Foundation University in Dumaguete City. Prior to its launch, the university's architecture program operated like traditional design studios, iterating upon modern forms and materials. These studios put emphasis on designs from cultures and climates that are out-of-touch with the tropical climate and socioeconomic issues facing the Philippines. It had been a dream of Foundation University's president to establish a design-build program patterned after those in the U.S., to give Filipino students hands-on experience using native materials in a context of community input and support. With this mission, Estudio Damgo was born. This paradigm shift in architecture education bridges the gap between social classes where students utilize their skills to innovate upon traditional building materials, like bamboo, which was otherwise stigmatized as a "poor man's material." The program also enables students to step into the work boots of the laborer to work along-side the people they are serving.

After the initial two years (2012 - 2014), the program gained the university national recognition and student achievement awards in bamboo construction and outreach initiatives. It also attributed to the title of the "Most Sustainable and 


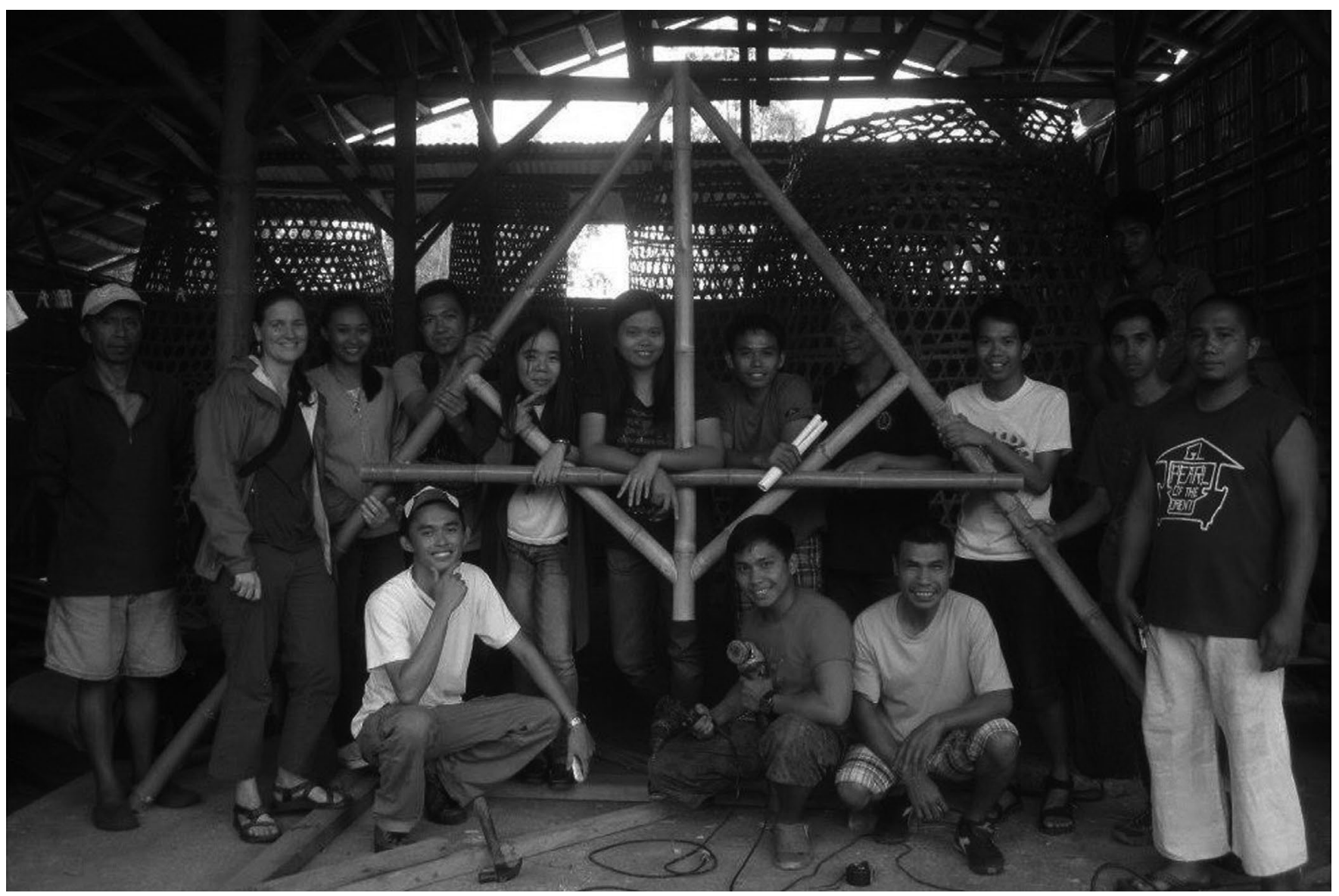

Figure 1: Estudio Damgo design-build bamboo workshop with Bambusa Collabo, the local bamboo farmers. Photo courtesy of Foundation University.

Eco-Friendly School" from the DENR-EMB in $2015 .^{3}$ These accomplishments prompted the study by the university to evaluate the first, three projects and institutionalize the program for long-term success.

The projects studied were: Estudio Damgo (ED) 1, a 435-square foot preschool classroom located in a rural mountain village (completed 2013); ED 2, an 840-square foot multipurpose hall for displaced flood survivors (completed 2014); and ED 3, a 1,140 -square foot floating guardhouse at the marine sanctuary (completed 2015).

\section{RESEARCH}

The research team, led by Anna Koosmann, an American architect and former Estudio Damgo instructor (2012 - 2014) who helped establish the program on ED 1 and ED 2, conducted research studies on the first, three Estudio Damgo projects over 5 months (August - December 2015) under a Fulbright Teaching and Research Grant. Koosmann collaborated with Foundation University's Research and Extension Director, Geraldine Quinones, and the College of Arts and Sciences, Maria Chona Z. Futalan Ph.D., Dean, Kriss Michael A. Tubog MPA, and ED 3 (2014 - 2015) alumni. Koosmann organized an advisory committee made up of university department heads, faculty, consulting architects, and program alumni to relay the findings and program development. The research team and the advisory committee met bimonthly, during the study period, to apply the research for program improvements.

The study commenced at a critical developmental period of the program. At the start of the study in August 2015, ED 1 and 2 structures were constructed and occupied, the third structure was approaching completion and occupancy, and the fourth project was in the design phase. The university saw value in the study for creating guidelines and recommendations in time for the construction on the fourth project. It was also timely to follow-up with the recipients of the completed projects for quality assurance and analytical comparison. It was necessary to identify best practices and transfer knowledge from past leaders to the current instructors. This was done through the advisory committee meetings throughout the study.

\section{METHOD}

The research was organized into three parts: questionnaires, POEs and site observations, and case studies; with the following objectives: 


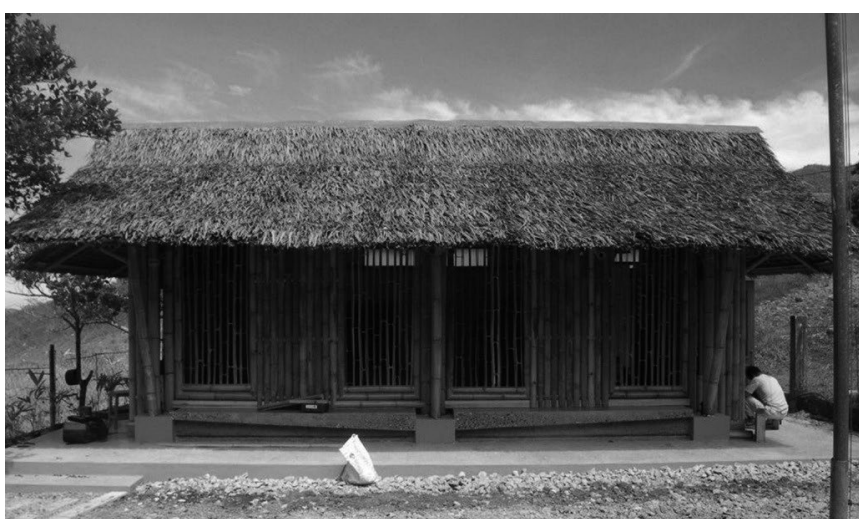

Figure 2: Estudio Damgo (ED) 1 Dungga Classroom completed 2013. (Credit: Foundation University)

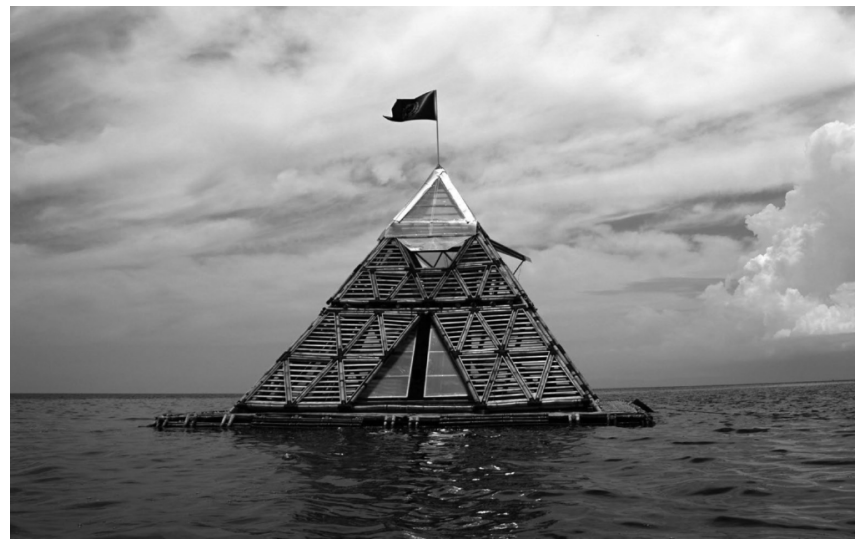

Figure 4: Estudio Damgo (ED) 3 Floating Marine Guardhouse completed 2015. (Credit: Anna Koosmann)

\section{Questionnaires:}

1. Identify impact of program on the architecture students;

2. Evaluate program on the target communities;

3. Evaluate problems encountered by students during project delivery;

4. Evaluate problems encountered by the communities after completion of the project;

5. Identify the sustainability of the project in relation to the community and the university;

6. Post-Occupancy Evaluations:

7. Evaluate the post-occupancy condition of the structures;

8. Evaluate the community ownership to the structures;

9. Case Studies:

10. Compare the program scope;

11. Compare the project scope and impact;

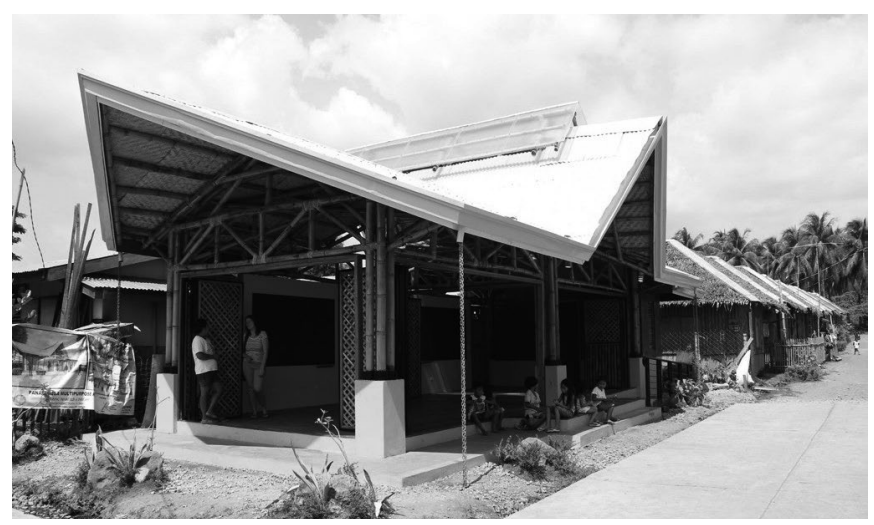

Figure 3: Estudio Damgo (ED) 2 Multipurpose Hall completed 2014. (Credit: Foundation University.)

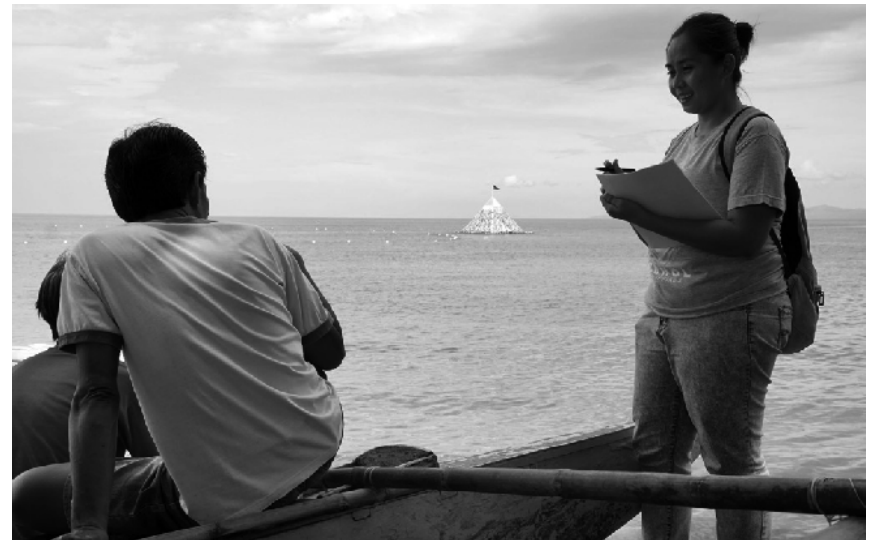

Figure 5: Estudio Damgo alumnus interviews two village residents from ED 3 Floating Marine Guardhouse for the research study in 2015. (Credit: Anna Koosmann)

\section{Transfer knowledge;}

13. Improve and institutionalize the program.

In August, the questionnaires were distributed to the program student alumni and recipient community respondents. POEs and site observations were conducted after the questionnaires. The research team traveled to the project sites for initial data collection and follow-up until the study was complete. The research team attended community meetings and collected the data for the case studies throughout the study period. Case studies were documented after the study completion. Midway through the study, ED 3 collapsed on October 30, 2015, five months after the construction was complete. The collapse negated POEs from that point forward, but project data was collected through December and evaluated and documented for the case study.

Questionnaires were completed by 12 Estudio Damgo alumni from the first, three years of the program $(2013-2015)$ and 57 community respondents from ED $2(2013-14)$. The questionnaires made use of percentage and weighted mean. The 


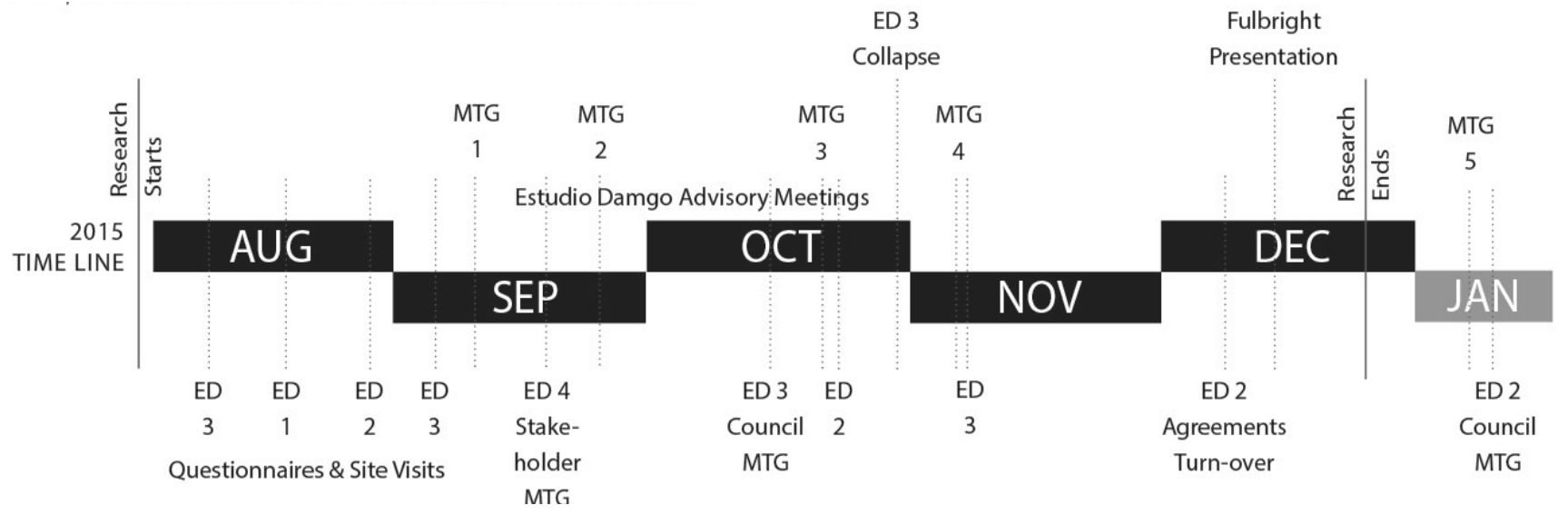

Figure 8: Research timeline of activities and events during the 5-month study. Image courtesy of Anna Koosmann..

responses were then tallied through MAC spreadsheet and the data was analyzed to find out if the objectives of the study were carried out. 16 residents from ED 1 were interviewed prior to the study. The results from this interview support the general findings from the questionnaires from ED 2. The structure at ED 3 was not complete and questionnaires were not distributed; however, feedback from ongoing site visits and community meetings were collected and included in the study.

POEs were conducted on three projects. The research team led site observations and walkthroughs to inspect the structure, material, and utility condition and operation. The team interviewed nearby residents and community stakeholders during the site visits. Photographs were taken of the structure in relation to areas that needed work or damage, and notable site improvements and changes. Photographs also documented the post-occupancy use of the structure.

Case studies were completed after the study period and utilized the data collection and analysis that was gathered throughout the study period. The research team attended community meetings for ED 2 and 3 . All meetings and interviews provided analytical comparisons in the POEs, site observations, and case studies. The information gathered was presented and discussed at the Estudio Damgo advisory committee meetings to improve future projects and curriculum changes.

\section{FINDINGS}

The questionnaire findings showed that students benefited from the hands-on experience and that it strengthened their personal attributes and community relations. Likewise, the communities reported a revival of the "Bayanihan Spirit" ${ }^{4}$ and they were grateful to be part of the program.

Post-occupancy evaluations documented the condition of the structures, materials, and utilities, while site observations assessed community ownership. The ED 1 preschool POE was conducted 2.5 years after occupancy and reported the building was in great condition. Materials showed little signs of weathering and the utilities were in working order. Site observations showed the school had a new net on the thatched roof (which aids in its maintenance) and the community had also added an outdoor kitchen and a new concrete walkway. These signs indicated the building was being maintained and owned.

The ED 2 multipurpose hall POE was conducted 1.5 years after occupancy and showed that the building was in great condition. Materials had no signs of weathering; however, the water utilities had not been hooked up. This resulted in additional follow-up and new agreements between the village and city administrators to clarify roles and responsibilities. Overall, site improvements indicated that the building was being maintained and owned.

The ED 3 floating guardhouse POE was conducted 3 months after construction and turnover. The structure was not occupied due to confusion over its readiness. The villagers were waiting for the students to make repairs and generally felt the structure would not hold up and refused to take on ownership until after typhoon season. Furthermore, the village council posted a sign stating, "Warning: Anyone caught using the Marine Guardhouse will be arrested and fined." The community's concerns were validated when the structure collapsed on October 30, 2015, the victim of tidal waves.

The Case studies compare the projects according to size, scope, schedule, cost, and impact. The information was summarized into best practices, lessons learned, and notable project attributes. The research findings and case studies were presented to the advisory committee and resulted in revisions to the curriculum and agreements, scope reduction, and capping budgets on future projects.

Project summaries showed the preschool was completed on time and with a surplus of funds which rolled over to the 


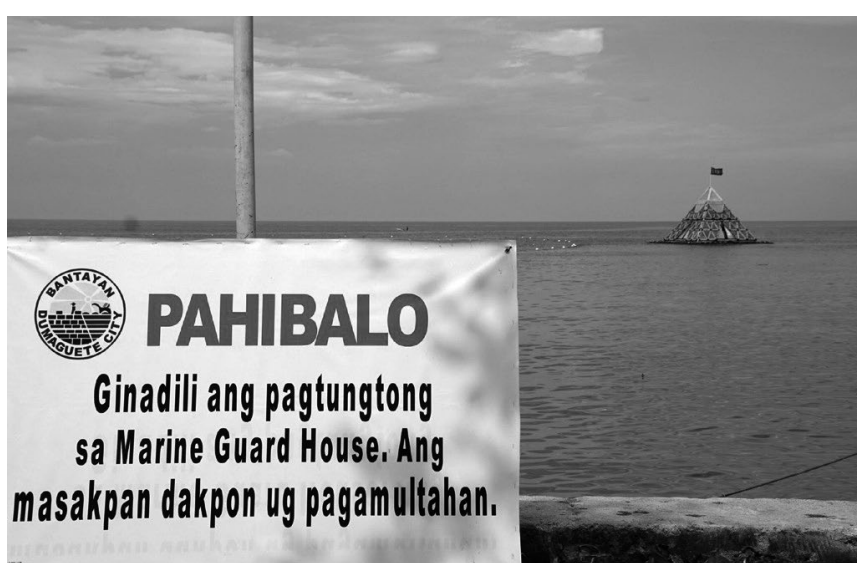

Figure 6: Sign posted by the village council says, "Warning: Anyone caught using the Marine Guardhouse will be arrested and fined." Photo courtesy of Anna Koosmann.

next project. The multipurpose hall was completed on time; however, it was larger and produced debts going into the next project. The floating guardhouse was larger still and costlier, and it was not finished on time.

Notable attributes in all the projects utilized locally grown bamboo, when properly treated and maintained, can last 20 years or more. At ED 1 and 2, bamboo columns are bundled for structural redundancy and can be replaced, if damaged. Large roof overhangs shield the rain and sun, and draw in breezes for passive cooling. Best practices at ED 1 and 2 include: working with city officials to identify projects, organizing community workshops early in the design phase with reviews for critical feedback, working on-site and involving the community during construction, and providing a maintenance plan at turnover. ED 3 students did not engage in a participatory process, the structure was prefabricated off-site, and they pushed through on a challenging design to float a structure without community buy-in, which resulted in a collapse. General lessons in planning for better site access and defining the roles and responsibilities of each party at every phase in the agreements.

The findings from the questionnaires were reviewed by the research team and reported in a university paper. ${ }^{5}$ After the POEs and site observations were conducted, the advisory committee addressed program needs, made curriculum changes, and the meetings served as a communication platform between university departments. The POEs and site observations revealed areas for improvement on the program and the target communities. ED projects 2 and 3 demonstrated confusion over the ownership of the structure. The research team followed-up the turn-over agreements between the recipient community and the university. New agreements were created for ED 2 to identify the recipient owners and users of

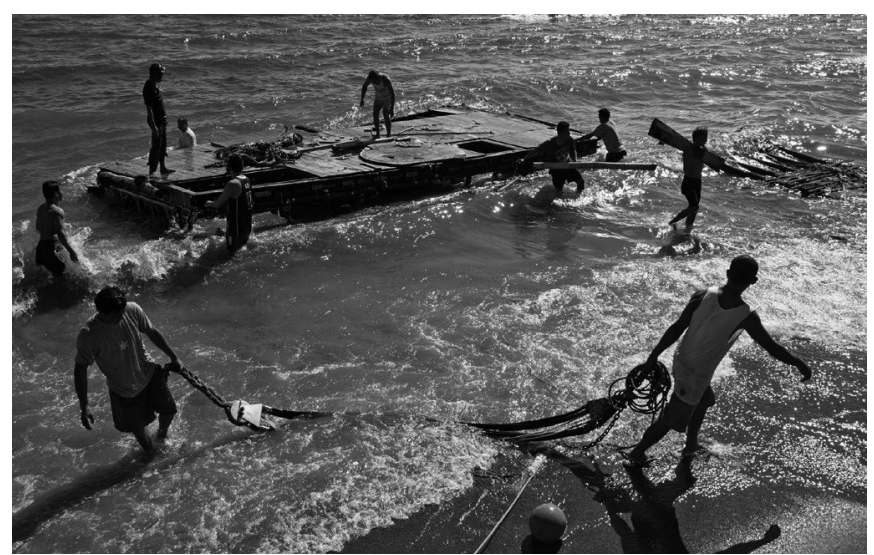

Figure 7: Foundation University crew tows in the remaining debris from ED 3 Floating Marine Guardhouse after the collapse on October 30 , 2015. Photo courtesy of Foundation University.

the structure for its intended use and maintenance. The ED 3 structure collapsed midway through the study and before the turn-over agreements were resolved for occupancy. This negated new agreements between ED 3 stakeholders and the university. The case studies generated guidelines, benchmarks, and recommendations for the Estudio Damgo program and future projects. These findings were presented to the advisory committee after the study was complete.

The research team was integral to the study because they had formed trusting relationships with the communities during the project development and construction before the study was conducted. This enabled easy site access on all three projects, thus expediting the research. Because the research team was active throughout the entire process prior to the study, they had more knowledge of the site conditions and community behaviors. This prior knowledge contributed to the analytical comparisons in the POEs, site observations, and case studies. In addition to the feedback from the recipient community, the research team received feedback from the social worker assigned to ED 2. Furthermore, attending community meetings and discussions presented valuable information from multiple perspectives by the community stakeholders perceptions of the projects, that were not addressed in respondent questionnaires, nor were they observed in the POEs and site visits.

\section{IMPACT}

The program impact on the students and the target communities is layered and will continue to be revealed overtime. Directly, the design-build program helps students acquire their full potential in structural design and actual construction by putting theory into practice, innovating upon and showcasing native materials; which in-turn, supports sustainable business practice and building resilient communities. Furthermore, the program has impacted the local businesses and artists 


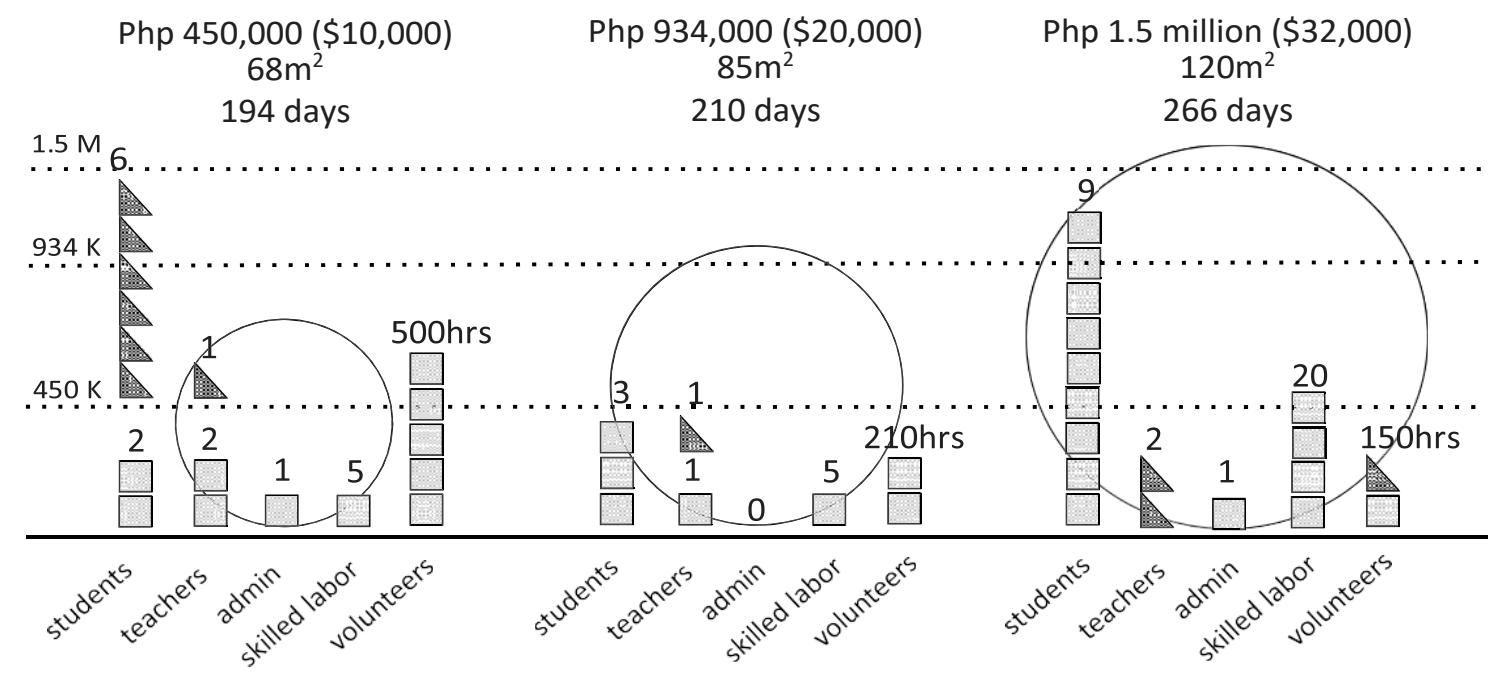

Figure 9: Case study project summaries. Image courtesy of Anna Koosmann.

through partnerships for fund-raising, music concerts, and art walks. It gave students a remarkable experience serving communities; likewise, the communities felt blessed to have met a group of individuals who gave them provisions needed for activities. Beneficiaries of ED 1 reported an increase in classroom attendance. The school has a subsidized lunch program and a space to hold parent-teacher meetings. ED 2 , by-in-large shows the greatest community impact, serving over 100 households of displaced flood survivors. The village captain reported an increase in meeting attendance and a decrease in neighbor disputes among the residents. ED 3 showed promise before its collapse. The Bantay-Dagat (fish wardens) reported sea grass growth under the floating structure and the potential for fish population increase at the marine sanctuary. The research findings have influenced positive changes to the program and leadership. It resulted in scaling back project size, cost, and bringing on professional consultants. Revisions to stakeholder agreements, clarify responsibilities and expectations at critical points during project development, construction, and turn-over. The study reinforces the importance of community buy-in during the design process, by creating and maintaining trusting relationships. It also shows the benefits of following-up with the beneficiaries and POEs after construction. The program instills a sense of empowerment for both the students and the target communities. Their mutual and full involvement in the project benefitted the entire community and has instilled the Filipino "Bayanihan Spirit" of working together to improve their community.

\section{RECOMMENDATIONS}

The research provides insights into the complexities of adapting a design-build pedagogy to reform Filipino architectural education and it reinforces the following practice:
- Build trust among community stakeholders, get community buy-in, and sign agreements;

- Involve the community in all phases of design and construction;

- Provide a maintenance plan and instruct owners on maintenance and operations;

- Follow-up and follow through, long-term success plays out after turnover and when the building takes on the life of its users.

Furthermore, the POEs, on-site interviews and observations, and attending community meetings provided information that the questionnaires lacked. Regular follow-up resulted in gaining greater detail of the successful outcomes in each project, as well as, uncovering the problems that needed attention.

Recommendations for Estudio Damgo's hands-on pedagogy extend its value beyond the building and design awards. Building and donating a structure alone does not guarantee success; rather, the complexity of social impact design engages communities in all phases of planning, design, and construction that addresses the needs expressed by the community. This is integral and conducive to best practices. Educating emerging professionals within their local communities is a promising alternative to foreign-aid and global initiatives tackling climate crisis from the outside. Storms like Super Typhoon Haiyan are becoming stronger and more frequent, putting the Philippines seasonally at risk. Estudio Damgo has begun to reform architecture education and revive the "Bayanihan Spirit" for educating the future leaders for building resilience. May Estudio Damgo continue forward and foster the spread of a local, architectural language inherent to Filipinos' place and cultural values to endure.

- Establish consistent and committed leadership; 


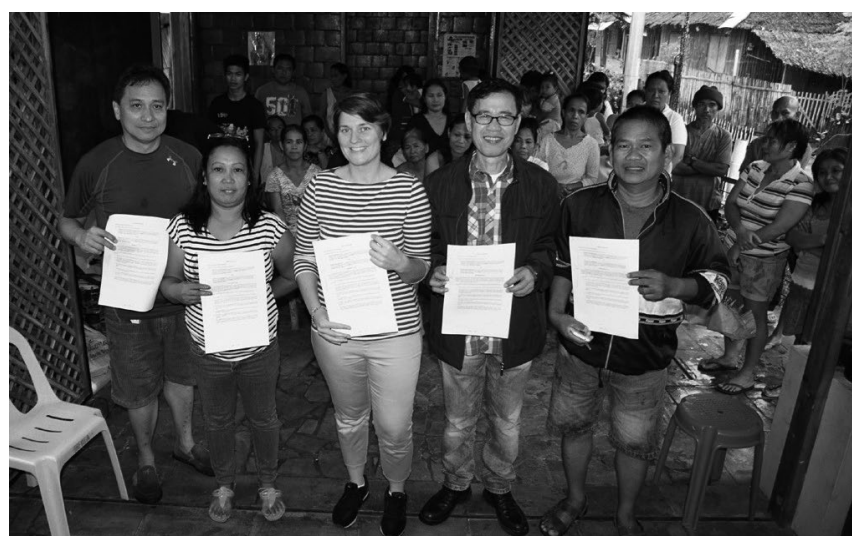

Figure 10: Estudio Damgo 2 revised turn-over agreements. Photo courtesy of Foundation University.

\section{ACKNOWLEDGEMENTS}

Theresearch was funded under a Fulbright Teaching and Research Grant from the U.S. State Department and the PhilippineAmerican Educational Foundation in 2015. The research received an Environmental Design Research Association (EDRA) CORE 2018 certification and it was presented at the national conference in Oklahoma City, OK on June 7, 2018. The research profile, "Evaluating the First Filipino Design-Build University," can be viewed at www.edra.org/page/2018_core_recipients.

The work and research would not take place without the dedication and support by Foundation University, Estudio Damgo Design-Build community, and its partners, including: the Philippines Department of Education; the City of Dumaguete; the Municipality of Valencia; the Barangays of Malaunay, Bajumpandan, and Bantayan; Core Shelter and Caritas 1 relief housing communities; Bambusa Collabo; Global Giving; Entheos; the Belltower project and numerous local, Filipino artists, business owners, volunteers, sponsors, donors, and supporters.

Learn more by visiting:

- www.facebook.com/EstudioDamgo

- www.teachphilippines.blogspot.com

- www.akoosmann.blogspot.com

- www.foundationu.com

- www.globalgiving.org

\section{REFERENCES}

Abendroth, Lisa M. and Bryan Bell. Public Interest Design Practice Guidebook. New York: Routledge, 2016.

Sustainable Native Communities Collaborative, www.susatainablenativecommunities.org.

The SEED Network, "SEED Evaluator 4.0," www.seednetwork. org/seed-evaluator-4-0.

\section{ENDNOTES}

1. Kraus, Chad. Designbuild Education. New York: Routledge, 2017

2. “Philippines Population 2015 Census," www.psa.gov.ph.

3. Department of Environment and Natural Resources. "Winners of National Search for Eco-Friendly Schools Recognized" www.denr.gov.ph November 25, 2015.

4. "Bayanihan Spirit" is a Filipino expression in the Visayan dialect that mean "people banding together to accomplish a difficult task" It refers to the Filipino tradition of lifting and moving a "nepa hut," or bamboo house on stilts, to a different location.

5. Maria Chona Z. Futalan et al., "The Impact of Estudio Damgo Program to Architecture Students and the Target Community," Dumaguete City, PH: College of Arts and Sciences, Foundation University, 2015. 